Año 13.

Revista de Investigación

Núm. 33

Académica sin Frontera

https://revistainvestigacionacademicasinfrontera.unison.mx/index.php/RDIASF

Recibido el 24 de agosto de 2020. Dictaminado mediante arbitraje favorablemente 18 de noviembre de 2020.

\title{
Contaminación de la basura en la cabecera municipal de Huatabampo
}

Dra. Laila Guadalupe Atrip Káram https://orcid.org/0000-0002-0283-244

M.A. Emma Cecilia Corral Morales https://orcid.org/0000-0002-0486-117X

Dr. Gil Arturo Quijano Vega https://orcid.org/0000-0002-0329-5858

C Saharabell Milagros Valencia Yocupicio. https://orcid.org/0000-0001-6348-6691

Tecnológico Nacional de México/ Instituto Tecnológico de Huatabampo

\section{Resumen}

Esta investigación, cuyo objetivo es dar a conocer toda la basura que sale a diario de casa y el por qué es tanta la contaminación en nuestra cabecera municipal, su objetivo es disminuir la contaminación y tener una solución al problema. Entre ello hacer posible el relleno sanitario para la disminución de la basura, con el cual el municipio no cuenta por falta de recursos, siendo así se lograría disminuir todos los desechos. Se elaboró una la investigación de campo para conocer la opinión de la ciudadanía con un total de 108 encuestas tomando en cuenta a un integrante por familia, así como a propietarios de algunos establecimientos de comida. Por otra parte, se entrevistó a la administración municipal donde cada regidor dio su punto de vista y opinión con respecto al problema de la contaminación, relleno sanitario y el servicio que se ofrece a la ciudadanía. A través de esta investigación se conoció que las familias no saben mucho sobre el tema y de ante mano están dispuestos a colaborar para la disminución de la contaminación, de igual manera los establecimientos de comida están dispuestos a colaborar personal y económicamente si es necesario. Mientras los regidores seguirán trabajando por un mejor servicio y la elaboración del relleno sanitario.

Palabras clave: contaminación de la basura, relleno sanitario, basura. 
Año 13.

Revista de Investigación

Núm. 33

Académica sin Frontera

https://revistainvestigacionacademicasinfrontera.unison.mx/index.php/RDIASF

Recibido el 24 de agosto de 2020. Dictaminado mediante arbitraje favorablemente 18 de noviembre de 2020.

\section{Abstract}

This investigation, whose objective is to publicize all the garbage that leaves the house every day and why there is so much pollution in our municipal seat, its objective is to reduce pollution and have a solution to the problem. Among this, make possible the sanitary landfill for the reduction of garbage, with which the municipality does not have due to lack of resources, being this way it would be possible to reduce all waste. A field research was carried out to find out the opinion of the public with a total of 108 surveys taking into account one member per family, as well as owners of some food establishments. On the other hand, the municipal administration was interviewed, where each councilor gave his point of view and opinion regarding the problem of pollution, sanitary landfill and the service offered to citizens. Through this research it was learned that families do not know much about the subject and are willing to collaborate in advance to reduce pollution, in the same way food establishments are willing to collaborate personally and financially if necessary. While the councilors will continue working for a better service and the development of the sanitary landfill.

Keywords: garbage pollution, landfill, garbage. 
Año 13.

Revista de Investigación

Núm. 33

Académica sin Frontera

https://revistainvestigacionacademicasinfrontera.unison.mx/index.php/RDIASF

Recibido el 24 de agosto de 2020. Dictaminado mediante arbitraje favorablemente 18 de noviembre de 2020.

\section{Introducción}

En la presente investigación trata de la contaminación de la basura en nuestra cabecera municipal, ya que será con el fin de dar conocer la problemática que afecta a nuestro entorno. Los rellenos sanitarios son obras que se utilizan para la disposición de residuos sólidos urbanos y a su vez no contaminar el medio ambiente, la contaminación es un factor principal de los rellenos y es por eso por lo que se deben de tomar en cuenta todas las medidas y estudios de control. El contexto de esta investigación se refiere a la contaminación que existe en la cabecera municipal de Huatabampo y sobre cómo podemos evitar tanta contaminación.

A través de todo lo expuesto se logró saber que falta mucho recurso, conciencia y educación para poder combatir la contaminación, por otra parte, se entiende que hace mucha falta el relleno sanitario para poder eliminar el basuron clandestino y evitar enfermedades, seria de buena ayuda dar platicas a ciudadanos y dueños de establecimientos para poder solucionar problemas de manera fácil. Uno de los grandes problemas que tenemos en el municipio es no contar con el adecuado servicio para la recolección de basura, los camiones no se dan abasto, para ello los habitantes toman sus propias medidas de tirar basura en espacios públicos o lugares prohibidos. Otro gran problema es no contar con los medios para depositar la basura ya recolectada, se lleva a un basuron clandestino a cielo abierto, donde por ello se produce más contaminación tanto al suelo como aire ya que la basura expulsa aromas, y esto puede llegar a provocar enfermedades respiratorias. Una solución a este problema sería la elaboración de un relleno sanitario donde la basura se llevará para su disposición final, y siendo así disminuir el impacto ambiental. 
Año 13.

Revista de Investigación

Núm. 33

Académica sin Frontera

https://revistainvestigacionacademicasinfrontera.unison.mx/index.php/RDIASF

Recibido el 24 de agosto de 2020. Dictaminado mediante arbitraje favorablemente 18 de noviembre de 2020.

\section{Planteamiento de problema}

El departamento de servicios públicos del H Ayuntamiento de Huatabampo presenta problemas para la recolección de basura debido a las fallas mecánicas de los recolectores, ya que están en uso constante las 24 horas del día y esto hace que se deterioren cada vez más, solo se cuenta con cuatro camiones para llevarlo a cabo con 18 rutas distintas. A causa de esto en ocasiones no se sale a recolectar la basura que al día vienen siendo 14 mil toneladas y es ahí cuando los ciudadanos deciden tomar otros medios para deshacerse de ella como quemarla, tirarla en lugares baldíos o en canales, y es ahí cuando surge el fenómeno de la contaminación.

Otro problema es que la cabecera municipal de Huatabampo no cuenta con relleno sanitario para tratar la basura, es por ello por lo que se lleva al basuron municipal ubicado a las afueras del municipio y esto provoca más contaminación. Además, dicho basuron se ha llegado a incendiar en dos ocasiones causando enfermedades respiratorias e infecciones por la contaminación del aire y el medio ambiente.

El municipio no cuenta con la cultura de separar la basura (vidrios, plásticos, latas, jeringas etc.) esto también afecta a los trabajadores de la recolección donde han tenido accidentes con los vidrios entre otras cosas. Se ha tomado las medidas de concientizar a la gente dando folletos, entregando volantes y haciendo visitas en todas las colonias en cada una de las casas, pero ha sido un fracaso porque los ciudadanos siguen tirando toda la basura junta, y es ahí que también afecta al camión recolector, por que al momento de jalar la basura se quedan latas atoradas y lo va dañando. 
Año 13.

Revista de Investigación

Núm. 33

Académica sin Frontera

https://revistainvestigacionacademicasinfrontera.unison.mx/index.php/RDIASF

Recibido el 24 de agosto de 2020. Dictaminado mediante arbitraje favorablemente 18 de noviembre de 2020.

\section{Antecedentes}

El municipio de Huatabampo se localiza al sur del Estado de Sonora, sus colindancias son las siguientes: al norte con el municipio de Etchojoa, Sonora; al sur con el municipio de Ahome, Sinaloa; al este con los municipios de Navojoa y Álamos, Sonora y al oeste con el Golfo de California. La cabecera municipal es la ciudad de Huatabampo, El municipio posee una superficie de 1,169.92 Kilómetros cuadrados que representa el 0.63 por ciento del total estatal y el 0.06 por ciento en relación al nacional; además de la cabecera municipal, cuenta con 10 comisarías como: Citavaro, Jupare, Etchoropo, Moroncarit, Yavaros, La Unión, Agiabampo, 10 de Abril y las Bocas. De acuerdo a los resultados que presenta la encuesta intercensal y el Consejo Estatal de Población 2015, el municipio contó con un total de 80,524 habitantes, de los cuales 40,185 eran hombres y 40,339 eran mujeres. El 62\% de la Población municipal vive en una de las 134 comunidades y localidades, de las cuales tenemos que el $80 \%$ son comunidades rurales menores de 500 habitantes, lo cual demuestra la gran dispersión de nuestros habitantes, que nos arroja una densidad de población de 64 habitantes por kilómetro cuadrado. En nuestro municipio la prestación de servicios públicos se puede definir con altibajos, debido a la falta de equipamiento como es, recolectores de basura en mal estado y obsoletos, y la escases de presupuesto para la adquisición de maquinaria y equipo en buen estado, para poder brindar un servicio de calidad y con oportunidad a la ciudadanía Huatabampense.

\section{Justificación}

Esta investigación debe realizarse ya que existen varios factores importantes que ocasionan la contaminación en el $\mathrm{H}$ ayuntamiento de Huatabampo como por el ejemplo la falta de mecánicos para los camiones recolectores los cuales transcurren la ciudad todo el día sin descanso los 7 días de la semana y por lo cual muchas veces no se puede hacer los recorridos 
Año 13.

Revista de Investigación

Núm. 33

Académica sin Frontera

https://revistainvestigacionacademicasinfrontera.unison.mx/index.php/RDIASF

Recibido el 24 de agosto de 2020. Dictaminado mediante arbitraje favorablemente 18 de noviembre de 2020.

como se deben ya que no se cuenta con ello al $100 \%$, otro factor importante es que no se cuenta con un relleno sanitario y es necesario ya que solo existe un basuron lo que implica muchas veces que se ocasionen incendio o incluso más contaminación, es por ello que este proyecto de investigación nos ayudara a mejorar nuestro municipio a estar más limpio y cómodo para vivir.

Aunque es relativamente fácil cuantificar el número de toneladas de basura que se producen, los datos disponibles revelan la importancia relativa que significa tratar de hallar una solución conjunta a la problemática que representa la basura, esto es, que la cantidad de basura crece, pero los espacios para almacenarla no, que la basura acumulada en grandes cantidades puede afectar el aire, el agua de los ríos, el agua de los mantos que utilizamos para consumo humano y el suelo de las tierras de cultivo, entre otros problemas.

En nuestro municipio es relativamente nuevo el que se pretenda introducir una nueva cultura para tratar la basura, como es el de clasificar los desperdicios de acuerdo con la clasificación señalada líneas atrás. Sin embargo, respecto a la basura inorgánica que puede ser reciclada, que es el tema general del presente trabajo, es necesario concientizar y sensibilizar a la población para que se conozca que dicha basura puede tener diversas utilidades antes de desecharse completamente, lo cual impactaría de diversas formas a la comunidad: desde crear empleo en la recolección, mejora del servicio público de limpia pública y reciclado de la basura inorgánica, hasta repercutir en la calidad de vida de la población misma.

\section{Objetivos}

\section{Objetivo general}

Diseñar una propuesta para contar con un relleno sanitario en la cabecera municipal de Huatabampo Sonora; partiendo de una investigación de campo, para analizar el impacto que este tendría en los sentidos social, ambiental y económico. 
Año 13.

Revista de Investigación

Núm. 33

Académica sin Frontera

https://revistainvestigacionacademicasinfrontera.unison.mx/index.php/RDIASF

Recibido el 24 de agosto de 2020. Dictaminado mediante arbitraje favorablemente 18 de noviembre de 2020.

\section{Objetivo especifico}

- Elaborar un plan al municipio para implementar el relleno sanitario.

- Crear planes de acción orientados al mejoramiento del servicio de recolección de basura.

- Desarrollar un sistema de reciclaje de vidrio, madera y plástico.

- Dar a conocer y aumentar la conciencia entre los ciudadanos, para la separación de la basura y no sea un problema para los recolectores.

\section{Referencias teóricas}

\section{Problemas por falta de relleno sanitario}

Hoy en día el problema de la contaminación ambiental figura entre las principales preocupaciones en la sociedad mundial debido a los efectos que este produce en la salud. Sin dudas los residuales peligrosos son una de las principales causas de contaminación ambiental. La vinculación de la salud humana y el sistema ambiental se presenta como una prioridad mundial por el carácter estratégico que significa para la sostenibilidad del desarrollo humano. Los residuos sólidos son un problema a nivel mundial que se agrava con la irresponsabilidad que se tiene al no cambiar nuestros hábitos de consumo y de, disposición final de nuestros residuos, que es el resultado de lo que a diario generamos en todas las actividades que realizamos ya sea en el trabajo, centro de estudio, hogar, centros recreativos, etc. Durante las últimas décadas ha surgido una gran preocupación ambiental y de salud por los problemas que originan los residuos, principalmente los denominados peligrosos. Esta preocupación nació en los países con mayor desarrollo económico, obligó a encarar los problemas de contaminación del medio ambiente y los daños que pueden ocasionarle a este y a la salud de la humanidad, y por tanto a los trabajadores; por la incorrecta disposición de los residuos 
Año 13.

Revista de Investigación

Núm. 33

Académica sin Frontera

https://revistainvestigacionacademicasinfrontera.unison.mx/index.php/RDIASF

Recibido el 24 de agosto de 2020. Dictaminado mediante arbitraje favorablemente 18 de noviembre de 2020.

peligrosos, son de una enorme importancia. El problema sanitario por la mala disposición de residuos incide en el riesgo epidemiológico que representa la acumulación y vertimiento incontrolado de excrementos, tienen como resultado de sus características de inflamabilidad (por su contenido pueden favorecer o causar fácilmente un incendio); proliferación de moscas, roedores, bacterias y otros animales y microorganismos causantes de enfermedad.

\section{Metodología}

\section{Población, universo, muestra}

El contexto de esta investigación se refiere a la contaminación que existe en la cabecera municipal de Huatabampo y sobre cómo podemos evitar tanta contaminación. Esto va dirigido a las personas en general siendo un total de 80524 habitantes de este municipio (Consejo Estatal de Población 2015) donde se tomó una muestra de 108 personas al azar a través de medios electrónicos, con el fin de conocer las causas de la contaminación, así como a establecimientos de comida con una población de 781 establecimientos, donde se tomó una muestra de 10 negocios de diferente giro.

\section{Tipo de estudio}

El diseño de esta investigación es de tipo mixto esto es porque se utilizaron instrumentos de recolección de tipo cualitativo y cuantitativo en lo principal por que se le realizo entrevista a algunos regidores del municipio. El análisis de las entrevistas fue a través de teoría fundamentada por dichas medidas que se tomaron al hacer la investigación lo cual permitió los factores que determinan la contaminación.

\section{Descripción de instrumentos}

Se aplican entrevistas a los diferentes establecimientos de comida para saber qué tanta basura produce y que medidas toman, con el objetivo de conocer el gran problema de basura en su 
Año 13.

Núm. 33

ISSN: 2007-8870

https://revistainvestigacionacademicasinfrontera.unison.mx/index.php/RDIASF

Recibido el 24 de agosto de 2020. Dictaminado mediante arbitraje favorablemente 18 de noviembre de 2020.

establecimiento y el servicio que se brinda el $\mathrm{H}$ ayuntamiento en cuanto a la recolección. De igual manera se aplicaron encuestas a integrantes de familia para saber qué tan informados están sobre el tema y con el objetivo de saber si están dispuestos a colaborar en la realización de actividades para la disminución de la contaminación. Por nuestra parte realizamos observaciones tomando en cuenta toda la información obtenida durante la aplicación de encuestas y entrevistas.

\section{Resultados}

Resultado del cuestionario aplicado a 10 establecimientos de comida, con el objetivo de conocer el problema de la basura en su establecimiento.

Los siguientes negocios fueron los analizados: Cocina Económica Quetzal, Birrieria Don Lupe, Sushis California, Pizzas La Abuela, Pizzas Little Caesars, Taquería La Mejor, Cenaduría Castros, Cenaduría Amelia, Hamburguesas Ajua, Hot Dogs.

1. Ocupación en el trabajo

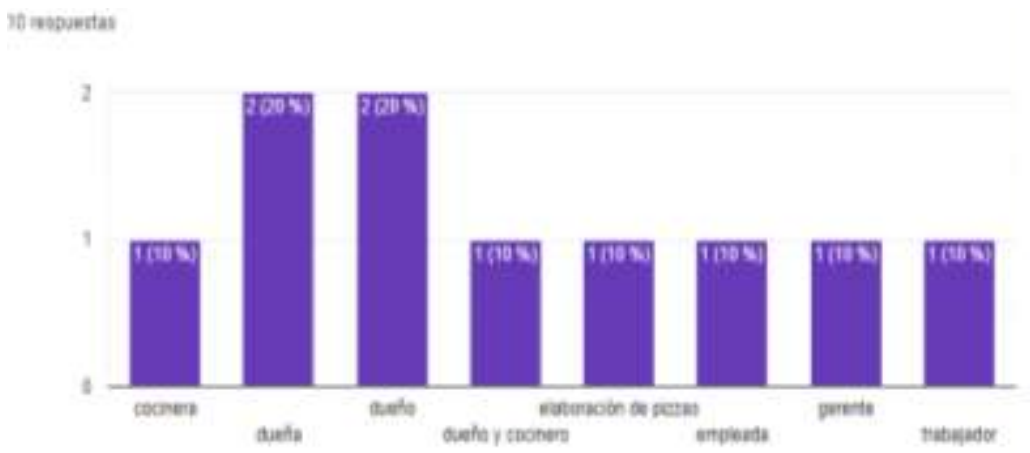

Grafico 1 ocupación del entrevistado 
Año 13.

Núm. 33

ISSN: 2007-8870

\section{https://revistainvestigacionacademicasinfrontera.unison.mx/index.php/RDIASF}

Recibido el 24 de agosto de 2020. Dictaminado mediante arbitraje favorablemente 18 de noviembre de 2020.

En esta grafica pudimos observar que hubo dos dueños y dos dueñas siendo los más altos de la gráfica.

2. Numero de empleados 10 respuestas

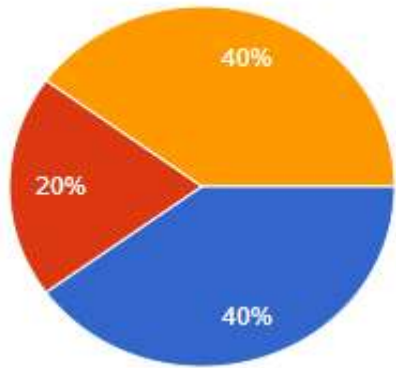

Grafico 2. Número de empleados

Se pueden considerar empresas pequeñas las que tienen el $40 \%$ de 1 a 3 empleados, así como empresas más pobladas con más de 5 trabajadores, reflejando otro $40 \%$ y solo un $20 \%$ tiene de 3 a 5 trabajadores.

3. Colonias de los establecimientos: colonia centro (9 negocios) y solo uno en la colonia 14 de enero

4.Tipo de negocio de comida

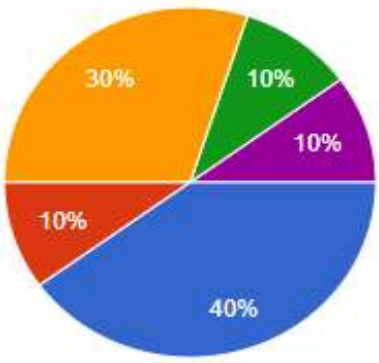

A. comida rápida (hamburguesas, tortas, burritos, pizzas)

B. comida oriental (sushis)

C. comida mexicana (Buffet, fritangas)

D. birria y mariscos

D Otros ¿qué tipo?

Grafico 3 tipos de comida en el negocio 
Año 13.

Núm. 33

ISSN: 2007-8870

https://revistainvestigacionacademicasinfrontera.unison.mx/index.php/RDIASF

Recibido el 24 de agosto de 2020. Dictaminado mediante arbitraje favorablemente 18 de noviembre de 2020.

Se puede observar que el establecimiento más común es el de comida rápida con un $40 \%$ y que con un $30 \%$ son las comidas mexicanas.

5. Cantidad de basura que sale por semana en su establecimiento (cuantos kilos, bolsas o botes de basura aproximadamente 3 bolsas negras jumbo diarias, aproximadamente 8 botes grandes diarios, de 10 a 20 kilos, 1 bolsa jumbo diaria, 3 botes grandes, 2 bolsas jumbo grandes, de 1 a 2 bolsas jumbo grandes, y dos botes grandes diarios en promedio por todos los establecimeintos encuestados

6. Tipo de basura que mas sale de su establecimiento

\section{0 respuestas}

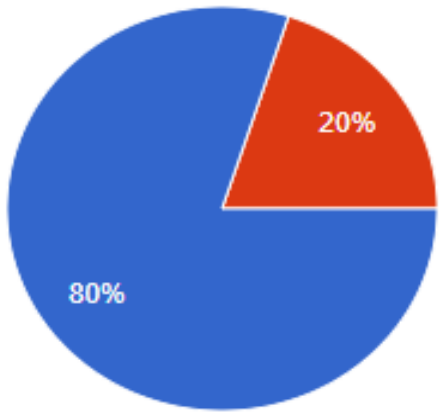

A. plástica, latas, botellas (bolsas y desechable)

B. cartón

C. desechos de comidas

D. otros (cuales)

Grafico 4. Tipo de basura que se desecha

El $80 \%$ es deseco de plastico entre botella y bolsa desechable y el resto lo ocupa el carton. 
Año 13.

Académica sin Frontera

Núm. 33

ISSN: 2007-8870

https://revistainvestigacionacademicasinfrontera.unison.mx/index.php/RDIASF

Recibido el 24 de agosto de 2020. Dictaminado mediante arbitraje favorablemente 18 de noviembre de 2020.

7.-¿Qué hace con los residuos de basura?

10 respuestas

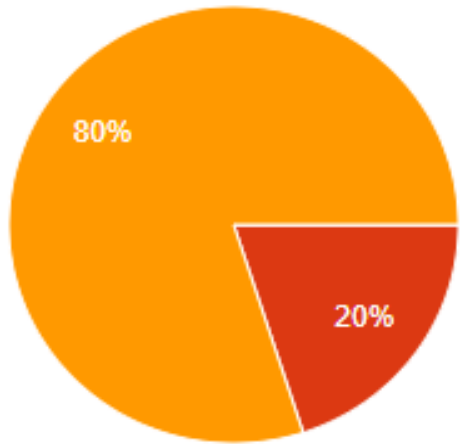

A. Se tira por sus propios medios

B. Se saca a la calle

C. Se espera a que pase el recolector de basura

D. Se utiliza otro medio ¿cuál?

Grafico 5. Destino de los desechos de basura

8. En su negocio, ¿clasifican la basura como orgánica e inorganica?


Grafico 6. Clasificación de la basura 
Año 13.

Núm. 33

ISSN: 2007-8870

https://revistainvestigacionacademicasinfrontera.unison.mx/index.php/RDIASF

Recibido el 24 de agosto de 2020. Dictaminado mediante arbitraje favorablemente 18 de noviembre de 2020.

9. ¿Qué días pasa el recolector de basura?

10 respuestas

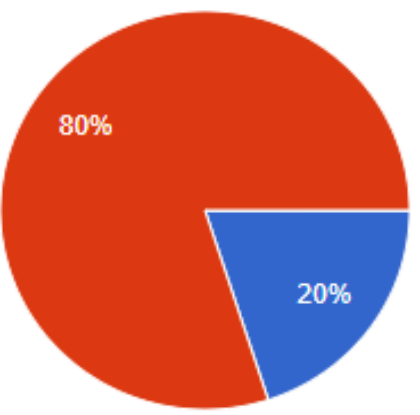

A. Todos los días

B. 102 días por semana

C. no tiene día fijo ¿Se dan abasto? sí o no

Grafico 7. Frecuencia de recolección de basura

En este grafico pudimos observar que el $80 \%$ dijo que solo pasa el recolector 1 o 2 veces por semana, y solo el $20 \%$ se realiza a diario.

10.¿Que es la contaminación?

10 respuestas

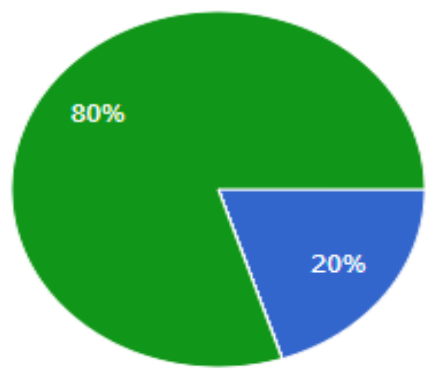

A) Que en el suelo haya basura tirada (bolsas de plástico, botellas, latas, etc.) B) Que huela mal

C) Que las áreas verdes, canales, caminos estén sucios de basura

D) Todas las anteriores

Grafico 8. Concepto de la contaminación

En esta grafica pudimos observar que el $80 \%$ de los establecimientos escogió todas las anteriores, considerando a la contaminación como huele mal, que en el suelo haya tirada basura y que las áreas verdes, caminos y canales estén sucios de basura. 
Año 13.

Núm. 33

ISSN: 2007-8870

https://revistainvestigacionacademicasinfrontera.unison.mx/index.php/RDIASF

Recibido el 24 de agosto de 2020. Dictaminado mediante arbitraje favorablemente 18 de noviembre de 2020.

11.- ¿Cuál es el verdadero problema que origina la contaminación?

10 respuestas

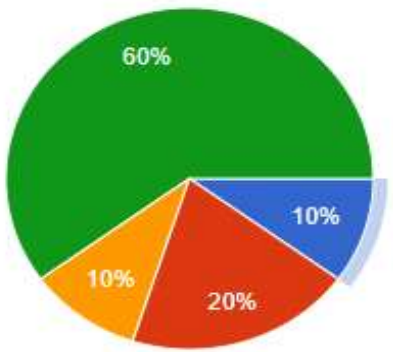

A. La falta de recolectores continuamente

B. Falta de conciencia

C. No les interesa el medio ambiente

D. Todas las anteriores

Grafico 9. Problema que origina la contaminación

Se puede observar que el $60 \%$ de los establecimientos dijo que el problema que origina la contaminación eran la falta de recolectores, la falta de conciencia y que no les interesa el medio ambiente

12. ¿Cómo ayudaría a evitar la contaminacion pensando en su negocio?

10 respuestas

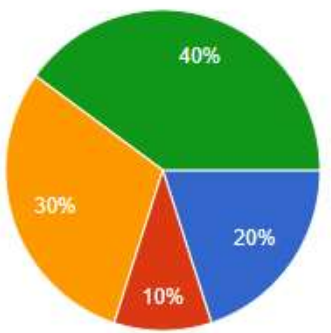

A. Participando en programas de

limpieza

B. reciclando la basura

C. separando la basura en orgánica e

inorgánica

D. Pidiendo más servicios de

recolección

Grafico 10. Apoyo para evitar la contaminación 
Año 13.

Núm. 33

ISSN: 2007-8870

https://revistainvestigacionacademicasinfrontera.unison.mx/index.php/RDIASF

Recibido el 24 de agosto de 2020. Dictaminado mediante arbitraje favorablemente 18 de noviembre de 2020.

En esta grafica pudimos observar que un $40 \%$ dijo que pidiendo más servicios y un $30 \%$ separando la basura, con $20 \%$ participando en programas en cargadas de la limpieza y solo un $10 \%$ reciclándola.

13.¿Quién debería de solucionar el problema de la contaminación?

10 respuestas

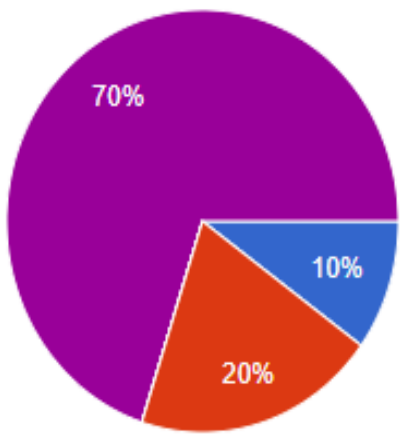

A. Los propios habitantes del municipio

B. El H ayuntamiento municipal

C. El gobierno estatal

D. Las instituciones gubernamentales ambientales

E. Todas las anteriores

Grafico 11. Responsabilidad de solucionar la contaminación.

En esta imagen podemos observar que el $70 \%$ considera que la responsabilidad esta tanto en los habitantes como en las dependencias de gobierno Municipal y Estatal 14. 
Año 13.

Núm. 33

ISSN: 2007-8870

https://revistainvestigacionacademicasinfrontera.unison.mx/index.php/RDIASF

Recibido el 24 de agosto de 2020. Dictaminado mediante arbitraje favorablemente 18 de noviembre de 2020.

14. ¿Estaría dispuesto a participar en algún programa para disminuir la contaminación 10 respuestas

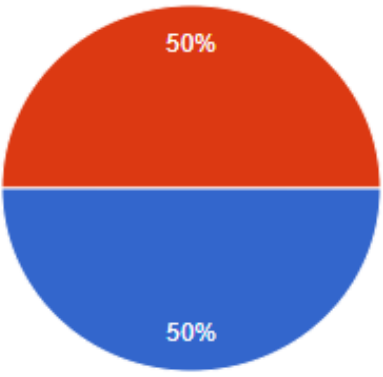

A. Totalmente de acuerdo

B. De acuerdo

C. En desacuerdo

Grafico 12. Disponibilidad en la participación de disminución de contaminación

Un 50\% dice si estar de acuerdo en participar en programas para disminuir la contaminación y el otro $50 \%$ totalmente de acuerdo.

15.¿Estaría dispuesto a colaborar económicamente para la elaboración del relleno sanitario?

10 respuestas

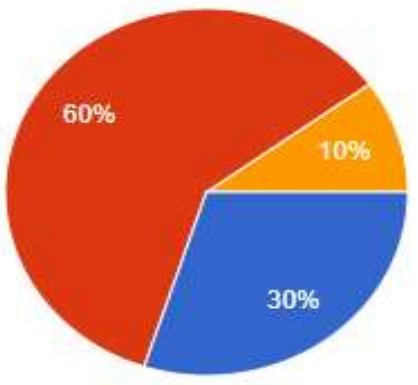

C. en desacuerdo

Grafico 13. Dsiponibilidad en la participación de que se realice el relleno sanitario 


\section{https://revistainvestigacionacademicasinfrontera.unison.mx/index.php/RDIASF}

Recibido el 24 de agosto de 2020. Dictaminado mediante arbitraje favorablemente 18 de noviembre de 2020.

Se puede observar que la mayoría estaría de acuerdo con colaborar económicamente para disminuir la contaminación.

16.- En su opinión, ¿cree que le hace falta a nuestro municipio el rellano sanitario para combatir la contaminación?

Debe haber más conciencia por parte de la ciudadanía en conjunto con el municipio, para que consigan más camiones recolectores y de ese modo no tendrían la basura afuera del establecimiento, otra observación es proporcionar contenedores de basura en lugares públicos, y lo principal crear conciencia en cada habitante a través de campañas de limpieza y recolección comunitaria.

Los resultados del cuestionario aplicado a 106 habitantes al azar de la cabecera municipal fueron los siguientes:

1.Rol de integrantes de la familia

106 respuestas

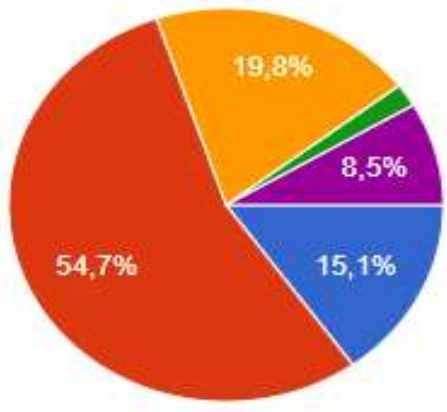


Núm. 33 ISSN: 2007-8870

https://revistainvestigacionacademicasinfrontera.unison.mx/index.php/RDIASF

Recibido el 24 de agosto de 2020. Dictaminado mediante arbitraje favorablemente 18 de noviembre de 2020.

La mayor parte de los encuestados fueron las madres de familia, por ser las que están más inmersas en las labores domésticas.

2.Número de integrantes de la familia

\footnotetext{
108 respuestas
}

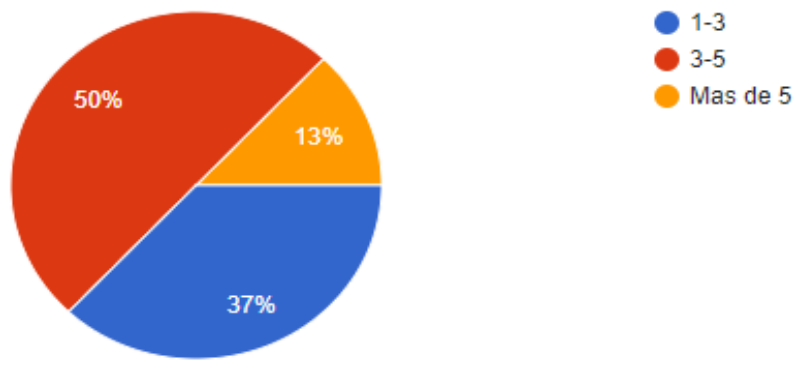

Grafico 2. Número de integrantes por familia

Se puede apreciar que un $50 \%$ de los encuestados son familias medianas con 3 a 5 integrantes, un $37 \%$ familias pequeñas con 1 a 3 integrantes, y solo el $17 \%$ con más de 5 miembros de familia.

3.- clase social

107 respuestas

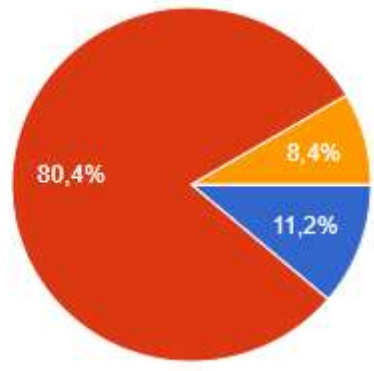


Año 13.

Núm. 33

ISSN: 2007-8870

https://revistainvestigacionacademicasinfrontera.unison.mx/index.php/RDIASF

Recibido el 24 de agosto de 2020. Dictaminado mediante arbitraje favorablemente 18 de noviembre de 2020.

En esta imagen podemos observar que el $0 \%$ de los encuestados pertenecen a una clase social media.

4.colonia o ubicación en la que vive el encuestado

Colonias: Centro, Fraccionamiento Díaz, colonia Ibarra, Fraccionamiento los juris, Colonia Independencia, entre otras

5.- Cantidad de basura que se acumula por semana en su hogar De 8 a 15 bolsas de mandado, 8 bolsas grandes por día, 5 kilogramos, 20 kilos y un promedio de 4 a 7 bolsas grandes.

6. Tipo de basura que más se sale

$$
106 \text { respuestas }
$$

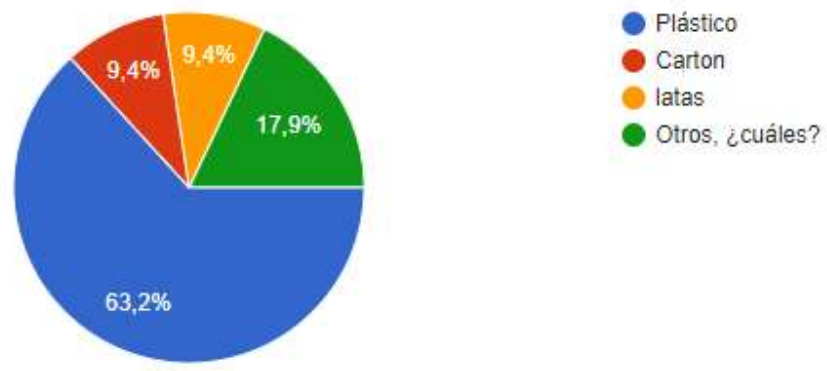

Grafico 4. Tipo de basura en el hogar

Se puede observar que con más del $60 \%$ la basura que más se usa es el plástico. 
Año 13.

Núm. 33

ISSN: 2007-8870

\section{https://revistainvestigacionacademicasinfrontera.unison.mx/index.php/RDIASF}

Recibido el 24 de agosto de 2020. Dictaminado mediante arbitraje favorablemente 18 de noviembre de 2020.

7. ¿Qué es la contaminación?

108 respuestas

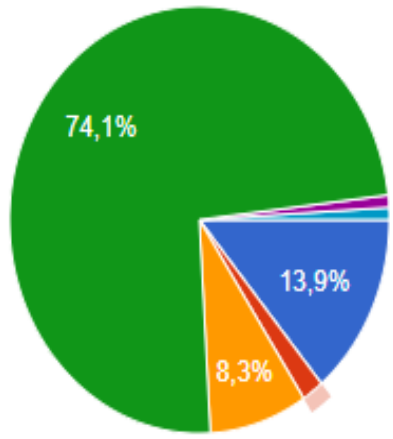

Que en el suelo haya basura tirada (bolsas de plástico, botellas, latas, etc.)

Que huela mal

Que las áreas verdes, canales, caminos estén sucios de basura

Todas las anteriores

- Es la presencia de algun componente nocivo ya sea algun agente quimico, fi..

La basura los quimicos k usan para la agricultura .los drenes

Grafico 5. Concepto que tienen de la contaminación

Más de $70 \%$ consideran a la contaminación como la basura tirada en el suelo, que huela mal y que las áreas verdes, canales y caminos estén sucios de basura, así como la presencia de componentes nocivos en algún agente químico y lo que estos se usan en la agricultura

8.-¿Cuál es el verdadero problema que origina la contaminación?

108 respuestas
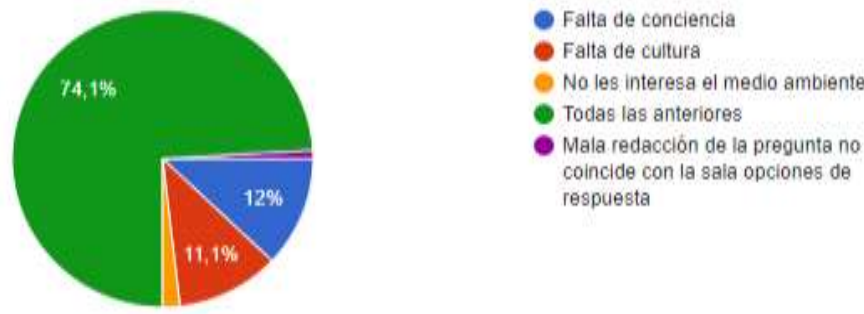

Mala redacción de la pregunta no coincide con la sala opciones de respuesta

Grafico 6. Problemas que originan la contaminación 
Recibido el 24 de agosto de 2020. Dictaminado mediante arbitraje favorablemente 18 de noviembre de 2020.

108 respuestas

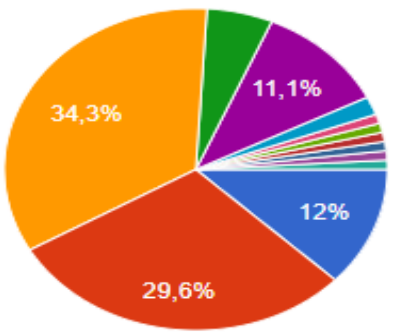

Participando en programas de limpieza

Promoviendo la recolección de basura.

Grafico 7. Opciones para evitar la contaminación

La razón más importante que se aprecia es el inculcarles a las nuevas generaciones el riesgo de la contaminación, seguido por no tirar la basura en espacios públicos, así como haciendo más campañas de recolección.

10.¿A sufrido alguna enfermedad originada por la contaminación?

108 respuestas

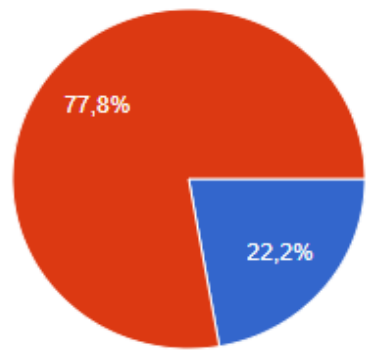


Año 13.

Núm. 33

ISSN: 2007-8870

https://revistainvestigacionacademicasinfrontera.unison.mx/index.php/RDIASF

Recibido el 24 de agosto de 2020. Dictaminado mediante arbitraje favorablemente 18 de noviembre de 2020.

Más del 70\% dicen no haber sufrido ninguna enfermedad.

11. Época del año que considerar hay más contaminación

108 respuestas

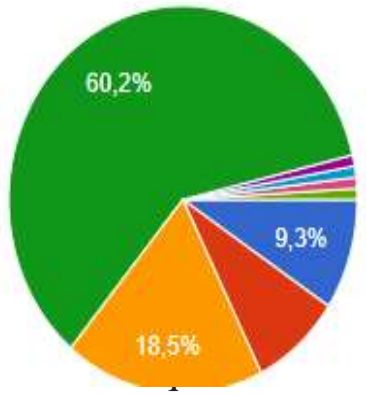

En época de lluvia

En época de sequias

En época de vientos

Todas las anteriores

- Epoca de trillas

- Época de trillas y quema de basurero

Siempre pero es mas en temporada de calor

Siempre hay, no se termina

contaminación

12. ¿Quién debe solucionar el problema de la contaminación?

108 respuestas

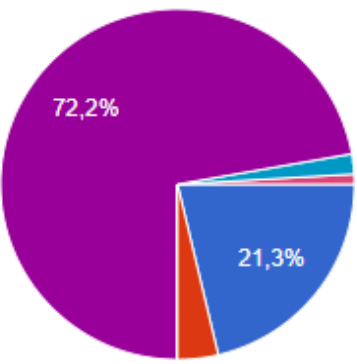

Los propios habitantes del municipio

- El H ayuntamiento municipal

El gobierno estatal

Las instituciones gubernamentales

ambientales

Todas las anteriores

Todos gobierno y ciudadanía

- Pienso que todos pero las intituciones tienes mas responsabilidad ya que ellos tienen el apoyo economico para hacer.

Grafico 10. Autoridad competente para resolver problemas de contaminación

En esta grafica más del $70 \%$ concluye que es responsabilidad tanto de los habitantes, como de los niveles de Gobierno Estatal y Municipal. 
Año 13.

Núm. 33

ISSN: 2007-8870

https://revistainvestigacionacademicasinfrontera.unison.mx/index.php/RDIASF

Recibido el 24 de agosto de 2020. Dictaminado mediante arbitraje favorablemente 18 de noviembre de 2020.

13. ¿Qué institución de gobierno ha implementado más acciones para combatir la contaminación?

$10 /$ respuestas

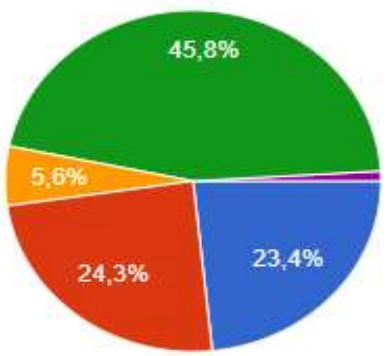

El H. ayuntamiento municipal

La secretaria de medio ambiente y recursos naturales

- La jurisdicción sanitaria municipal

Ninguna de las anteriores

No se

Grafico 11. Instituciones de gobierno que implementan acciones contra la contaminación

Se considera delicada la respuesta de los usuarios que opinan que ninguna orden de gobierno ha implementado estas acciones, siendo el $45 \%$ correspondiente a esa negativa respuesta, seguida por el $24 \%$ que corresponde a la secretaria del medio ambiente y recursos naturales, y con un $23 \%$ ha participado el Ayuntamiento Local

14.- ¿Estaría dispuesto a participar en algún programa para disminuir la contaminación?

108 respuestas

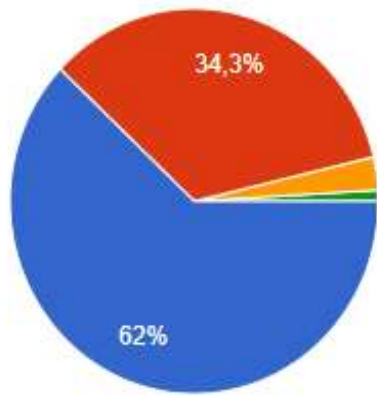

Totalmente de acuerdo

De acuerdo

En desacuerdo

No 
Año 13.

Revista de Investigación

Académica sin Frontera

Núm. 33

ISSN: 2007-8870

https://revistainvestigacionacademicasinfrontera.unison.mx/index.php/RDIASF

Recibido el 24 de agosto de 2020. Dictaminado mediante arbitraje favorablemente 18 de noviembre de 2020.

En esta grafica pudimos observar que un $62 \%$ estarían totalmente de acuerdo con ayudar en algún programa para disminuir la contaminación, seguido por un 34\% que solo están de acuerdo.

15. En su opinión, ¿Cree que hace falta un relleno sanitario? ¿Por qué?

La mayoría de los entrevistados opinan que, si es necesario, y útil porque la basura debe estar en su lugar, para disminuir la contaminación y así no dejarla en el basurón porque eso hace que sea demasiada la acumulada.

16. Estaría dispuesto a colaborar económicamente para la elaboración del relleno sanitario
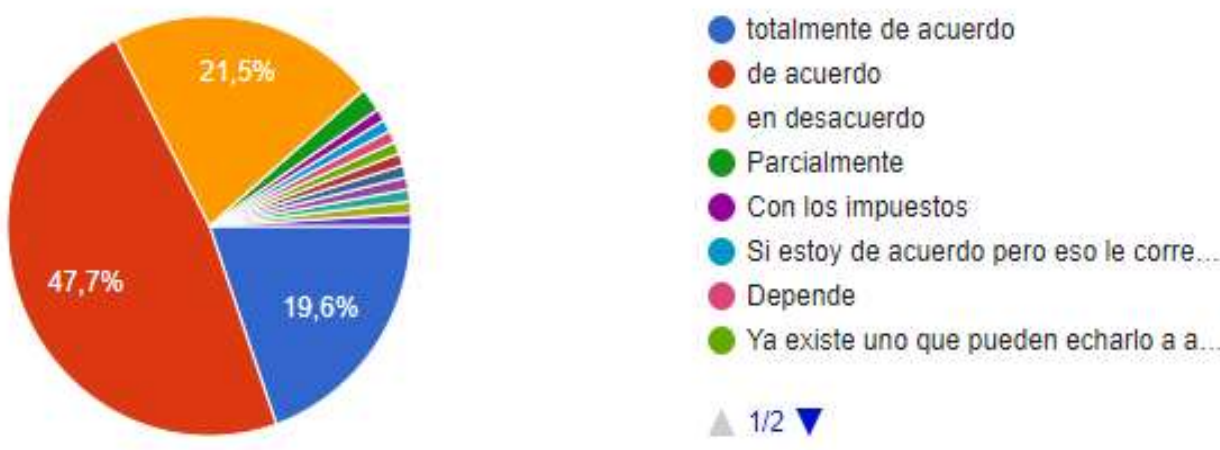

Grafico 13. Disponibilidad económica para la construcción del relleno sanitario

Se observa que el $47 \%$ si está de acuerdo, solo el $21.5 \%$ ea en desacuerdo, considerando un $19.5 \%$ estar totalmente de acuerdo en apoyar.

Conclusiones y propuestas

El manejo de la basura en la cabecera municipal es aún deficiente, faltando un relleno sanitario que siga todas las normas técnicas necesarias para evitar que la basura se convierta en un problema ambiental. Y de ser así dejar de usar el basuron clandestino. Determinadas 
Año 13.

Revista de Investigación

Núm. 33

Académica sin Frontera

https://revistainvestigacionacademicasinfrontera.unison.mx/index.php/RDIASF

Recibido el 24 de agosto de 2020. Dictaminado mediante arbitraje favorablemente 18 de noviembre de 2020.

áreas de la cabecera municipal se utiliza como basureros o depósitos informales de basura, lo que constituye un problema ambiental ya que ésta se convierte en focos de producción de contaminantes, ya sea por la quema informal de ésta basura (incluso dentro del casco urbano), y un gran problema en la salud de las personas, por ser un lugar propicio para la reproducción de organismos vectores o transmisores de enfermedades como zancudos, ratas, cucarachas, etc.

La recuperación de materiales implica diversas opciones muchas veces complementarias como por ejemplo rehusar, reciclar, reparar. La idea es promover en el ámbito de gobiernos, empresas, instituciones y personas, lo que hemos denominado cultura. En un sentido amplio podemos decir que aceptar la cultura supone tener una actitud amigable con el ambiente, usar racionalmente los recursos naturales, no contaminar el medio ambiente, evitar la generación de basura.

Propuestas.

Hazte responsable de la basura que generas y tírala de forma adecuada y en los lugares adecuados. Reduce la cantidad de basura que generas. Separa siempre la basura que generas en orgánica, inorgánica no-reciclable, inorgánica reciclable y residuos de manejo especial y asegúrate de que los camiones recolectores y barrenderos se la lleven. Infórmate sobre la manera adecuada de disponer de tus residuos: aceites de cocina o de maquinaria, recipientes de insecticidas, artículos de curación o higiene personal, animales y mascotas muertos. Así evitarás contaminación y enfermedades. Organízate con tus vecinos y tus autoridades locales para que se coloquen contenedores en la vía pública y se amplíen las rutas de recolección y limpia. Exige a tus familiares, amigos, vecinos y a tus autoridades que se hagan responsables de cuidar su comunidad. 
Año 13.

Revista de Investigación

Núm. 33

Académica sin Frontera

ISSN: 2007-8870

https://revistainvestigacionacademicasinfrontera.unison.mx/index.php/RDIASF

Recibido el 24 de agosto de 2020. Dictaminado mediante arbitraje favorablemente 18 de noviembre de 2020.

\section{Referencias}

Cano,Geronimo (1992). ciencias ambientales y desarollo sustentable. mexico: Ed. Thomson.

Daz Cautiño Reynol, S. E. (2009). Desarrollo sustentable oportunidad para la vida. Mexico: Ed Mc graw hill.

G, T. M. (2007). Ciencia ambiental, desarrollo sustentable, enfoque integral. Mexico: Ed. cengage learning. 
Año 13.

Revista de Investigación

Núm. 33

Académica sin Frontera

https://revistainvestigacionacademicasinfrontera.unison.mx/index.php/RDIASF

Recibido el 24 de agosto de 2020. Dictaminado mediante arbitraje favorablemente 18 de noviembre de 2020.

\section{Directorio Institucional}

Dr. Enrique Fernando Velázquez Contreras

Rector

Dr. Ramón Enrique Robles Zepeda

Secretario General Académico

Dra. Rosa María Montesinos Cisneros

Secretaria General Administrativa

Dr. Rodolfo Basurto Álvarez

Director de Vinculación y Difusión

Dra. Adriana Leticia Navarro Verdugo

Vicerrectora de la Unidad Regional Sur

Dr. Ernesto Clark Valenzuela

Director de la División de Ciencias Económicas y Sociales

Dr. Francisco Espinoza Morales

Secretario de la División de Ciencias Económico y Sociales

Dra. Leticia María González Velásquez

Jefe del Departamento de Ciencias Económico Administrativas

Dra. Lidia Amalia Zallas Esquer

Jefe de Departamento de Ciencias Sociales 
Año 13.

Revista de Investigación

Núm. 33

Académica sin Frontera

https://revistainvestigacionacademicasinfrontera.unison.mx/index.php/RDIASF

Recibido el 24 de agosto de 2020. Dictaminado mediante arbitraje favorablemente 18 de noviembre de 2020.

\section{Comité Directivo}

\section{Editor Responsable}

Dr. Francisco Espinoza Morales

\section{Directora}

Dra. Leticia María González Velásquez

\section{Subdirector}

Dr. Javier Carreón Guillen

\section{Editor Científico}

Dr. Cruz García Lirios

\section{Master Gráfico}

M.T.I. Francisco Alan Espinoza Zallas

Nos complace anunciar que su diario, "Academic Research Journal Withoutborders" (ISSN/EISSN 2007-8870) fue evaluado positivamente en la indexación Citefactor, ahora la página de la revista está disponible en línea, en caso de cualquier problema.

Journals Master | International Innovative Journal Impact Factor (IIJIF)

Red Latinoamericana de revistas Académicas en Ciencias Sociales y Humanidades

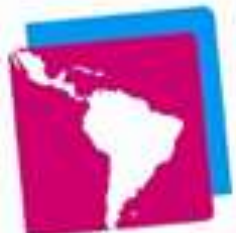

LatinREV




Año 13.

Revista de Investigación

Núm. 33

Académica sin Frontera

https://revistainvestigacionacademicasinfrontera.unison.mx/index.php/RDIASF

Recibido el 24 de agosto de 2020. Dictaminado mediante arbitraje favorablemente 18 de noviembre de 2020.

\section{Comité editorial}

Dra. Angélica María Rascón Larios

Universidad de Sonora. México

Dra. María del Rosario Molina González

Universidad de Sonora

Dra. Francisca Elena Rochin Wong

Universidad de Sonora. México

Dra. Lidia Amalia Zallas Esquer

Universidad de Sonora. México

Dra. Beatriz Llamas Arechiga

Universidad de Sonora. México

Dr. Rogelio Barba Álvarez

Universidad de Guadalajara. México

Dra. Rosa María Rincón Ornelas

Universidad de Sonora. México

Dr. Juan Flores Preciado

Universidad de Colima. México

Dr. Amado Olivares Leal. Universidad de Sonora

Universidad de Sonora. México

Dr. Guillermo Velázquez Valadez.

Instituto Politécnico Nacional (IPN) México

Dr. Hugo Nefstalí Padilla Torres.

Universidad Estatal de Sonora. México

Dr. Luis Ramón Moreno Moreno.

Universidad Autónoma de Baja California. México

Dr. Miguel Ángel Vázquez Ruiz.

Universidad de Sonora. México 
Año 13.

Revista de Investigación

Núm. 33

Académica sin Frontera

https://revistainvestigacionacademicasinfrontera.unison.mx/index.php/RDIASF

Recibido el 24 de agosto de 2020. Dictaminado mediante arbitraje favorablemente 18 de noviembre de 2020.

Dra. Lorena Vélez García.

Universidad Autónoma de Baja California. México

Dra. Pabla Peralta Miranda.

Universidad Simón Bolívar, Barranquilla, Colombia

Mtro. Roberto Espíritu Olmos

Universidad de Colima (FCA Tecomán) Colima

Dr. Héctor Priego Huertas.

Universidad de Colima (FCA Tecomán) Colima

Mtra. María Guadalupe Alvarado Ibarra.

Universidad de Sonora. México.

MSc. Celso Germán Sánchez Zayas

Universidad de Camagüey, Ignacio Agramonte Loynaz, Cuba

Dra. María Luisa Quintero Soto

Universidad Autónoma del Estado de México

Dr. Eyder Bolivar Mojica

Universidad Católica, Luis Amigó, Medellin, Colombia

Revisores de Textos en Inglés

Mtro. Renato Encinas

Mtra. Cecilia Guadalupe Martínez Solano

Comité científico

Dr. Rosendo Martínez Jiménez. Universidad Autónoma Benito Juárez de Oaxaca.

Dr. Hugo Neftalí Padilla. Universidad Estatal de Sonora

Dra. María Teresa Gaxiola Sánchez. Universidad de Sonora.

Dr. José Cesar Kaplan. Universidad Estatal de Sonora.

Dr. Alfredo Islas Rodríguez. Universidad de Sonora

Frecuencia de publicación: semestral / 2 números por año. 
Año 13.

Revista de Investigación

Núm. 33

Académica sin Frontera

ISSN: 2007-8870

https://revistainvestigacionacademicasinfrontera.unison.mx/index.php/RDIASF

Recibido el 24 de agosto de 2020. Dictaminado mediante arbitraje favorablemente 18 de noviembre de 2020.

Revista de Investigación Académica sin Frontera (RIASF) con (ISSN: 2007-8870) es un interlocutor internacional de acceso abierto revisado diario en línea en el ámbito del de las Ciencias Económicas Administrativas y Sociales. Su objetivo principal es dar a los trabajos de investigación de calidad. Cubre todas las sub-campos de los campos anteriormente mencionados. Proporciona la plataforma a académicos, estudiantes y profesionales. Sólo pública trabajos de investigación y artículos de revisión inicial. Documento presentado debe cumplir con algunos criterios como, debe ser original, inédita y no estén sometidos a ninguna otra revista.

RIASF es una revista arbitrada / Revisión por pares International. Publicamos documentos sobre una variedad de temas, contextos y estrategias de análisis que examinan la relación entre la rápida evolución para la Sociedad y la tecnología del conocimiento.

REVISTA DE INVESTIGACIÓN ACADÉMICA SIN FRONTERA, Año 13, No. 33, Julio - diciembre 2020, es una publicación semestral de investigación científica, editada por la Universidad de Sonora, a través de las División de Ciencias Económicas y Sociales, de la Unidad Regional Sur, Blvd. Lázaro Cárdenas No. 100, Col. Francisco Villa, Navojoa, Sonora, Sonora, México, C.P. 85880. Tel. (642) 42599-54.

http://www.revistainvestigacionacademicasinfrontera.com/, revistaacademicasinfrontera@ unison.mx. Editor responsable: Francisco Espinoza Morales. Reserva de Derechos al Uso Exclusivo: 042013-121811323700-203 e ISSN: 2007-8870, ambos otorgados por el Instituto Nacional de Derecho de Autor. Inscrita en el Directorio de LATINDEX, con Núm. De folio 20014, folio único 14590. Responsable de la última actualización de este Número, Unidad Informática de la Universidad de Sonora, fecha de la última modificación, 30 de diciembre 2020, indexada a Cite Factor Academic Scientific Journal y Journals Master (IIJIF) y Red Latinoamericana de Revistas Académicas en Ciencias Sociales y Humanidades, (Latín Rev). Las opiniones expresadas por los autores no necesariamente reflejan la postura del editor de la publicación. Se autoriza la reproducción total o parcial de los contenidos e imágenes en la presente publicación siempre y cuando se cuente con la autorización del editor y se cite plenamente la fuente. 
Recibido el 24 de agosto de 2020. Dictaminado mediante arbitraje favorablemente 18 de noviembre de 2020.

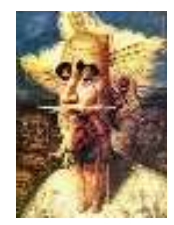

Nos complace anunciar que su diario, "Academic Research Journal Withoutborders" (ISSN/EISSN 2007-8870) fue evaluado positivamente en la indexación Citefactor, ahora la página de la revista está disponible en línea, en caso de cualquier problema.

Journals Master | International Innovative Journal Impact Factor (IIJIF)

\section{Red Latinoamericana de revistas Académicas en Ciencias Sociales y Humanidades}
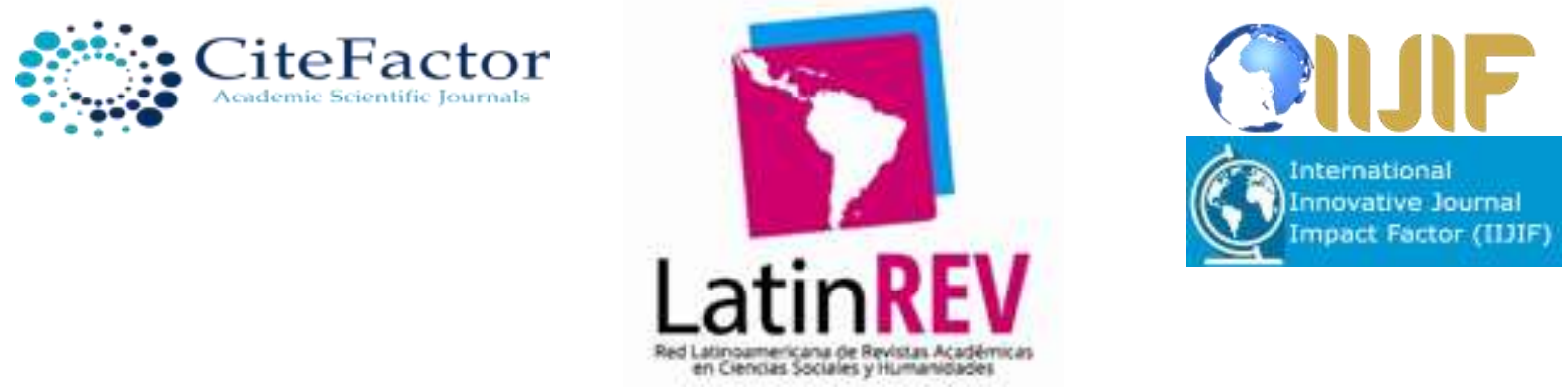

https://www.neliti.com
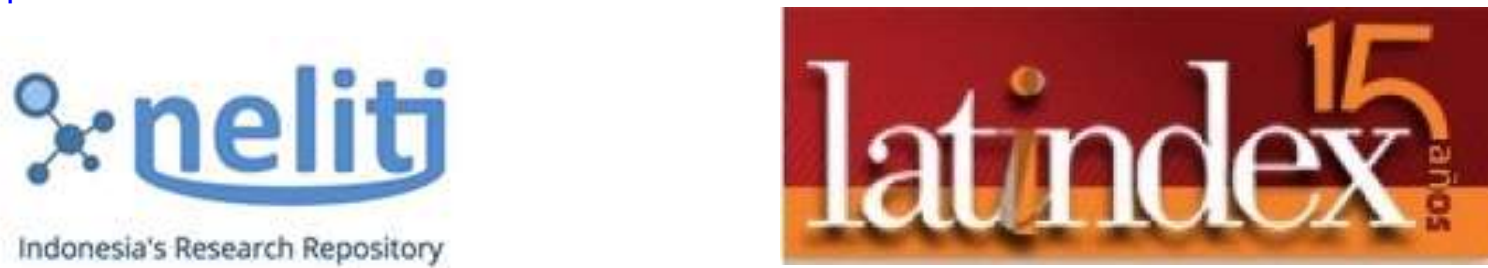

Indonesia's Research Repository

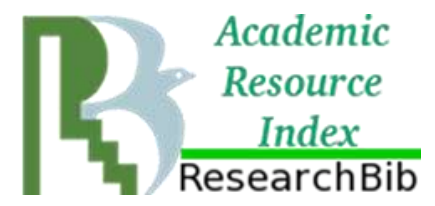

Eurasian

Journal

www.ESJIndex.org
Academic

Resource

ResearchBib 
Revista de Investigación

Año 13.

Académica sin Frontera

Núm. 33

ISSN: 2007-8870

https://revistainvestigacionacademicasinfrontera.unison.mx/index.php/RDIASF

Recibido el 24 de agosto de 2020. Dictaminado mediante arbitraje favorablemente 18 de noviembre de 2020. 